\title{
Dietary and physical activity patterns of school children in an urban area of Sri Lanka.
}

\author{
VP Wickramasinghe ${ }^{1}$, Sanath P Lamabadusuriya ${ }^{2}$, N Atapattu ${ }^{3}$, G Sathyadas $^{1}$, S Kuruparananthan $^{3}$, \\ P Karunarathne ${ }^{3}$
}

Sri Lanka Journal of Child Health 2005; 34: 44-9

(Key words: physical activity, tuition, obesity, overweight, thinness)

\begin{abstract}
Objective To provide information on nutritional status and dietary and physical activity pattern of 812 year old school children in an urban area of Sri Lanka.
\end{abstract}

Method Seven schools in Colombo were randomly selected. These schools showed a fair representation of children of all social levels. Students of years 4, 5, 6 and 7 were included. 50 students from each grade of each school were randomly selected and recruited into study. The purpose of study was explained to the students and any withdrawals allowed. Medical officers performed the anthropometric measurements. Height was measured using a stadiometer and weight using an electronic weighing scale. Medical assessment was done in all children who participated in study. To define obesity and overweight, sex and age specific body mass index (BMI) cutoffs recommended by International Obesity Task Force were used. Age and sex specific BMI 5th percentile from revised NCHS (2000) growth charts were used to define thinness. Information regarding physical activity, behaviour, feeding practices and socioeconomic factors were obtained using a pretested questionnaire filled by parent/guardian. Data was analyzed using Epi Info 2000 (CDC, USA) software.

Results One thousand two hundred and sixty six children were recruited to the study. Data of 1224 subjects were used in the anthropometric analysis, while 1102 data sets were used in analysis of dietary and physical activity. Of the latter group $44 \%$ were boys. The children belonged to 3 types of schools

${ }_{1}^{1}$ Lecturer, ${ }^{2}$ Senior Professor, Department of
Paediatrics, Faculty of Medicine, University of
Colombo, ${ }^{3}$ House Officer, Professorial Unit, Lady
Ridgeway Hospital, Colombo.

(Received on 28 December 2003) based on type of administration. About $12 \%$ each were from ages 8 and 12; the rest were almost equally distributed among the other 3 age categories. More than $80 \%$ of mothers had a level of education above GCE (O/L). 60.8\% watched television for 1-2 hours each day during weekdays and $39.5 \%$ watched television for 3-4 hours during weekends. More than $50 \%$ engaged in daily physical activity for more than one hour during weekdays as well as weekends. $80.1 \%$ attended tuition classes. A similar distribution was seen in all age groups. Although consumption of vegetables was high, fruit consumption was not satisfactory. Majority had eggs or fish as their main source of protein. Prevalence of obesity and overweight increased with increase in family income and thinness was high among low socio-economic groups. Dental caries was the commonest health problem. Highest prevalence was among children from public non-national schools $(48.7 \%)$, whilst public national and private schools had a prevalence of $10.5 \%$ and $11.8 \%$ respectively. Of the skin lesions commonest was scabies.

Conclusion The main factor that influenced the nutritional status and related behaviour was the socioeconomic standard. Health programmes should be designed targeting these groups.

\section{Introduction}

The lifestyle and diets of children are changing rapidly in response to social and cultural changes in society. Availability of fast food outlets, pre-prepared food and flavoured food and beverages have influenced feeding practices. Spending more time on viewing television, involvement in computer games and attending extra classes outside school hours have contributed to reduction in physical activity. These have led to an increase in prevalence of overweight and obesity. But this has not occurred uniformly in the entire society and malnutrition has not been controlled yet. This study was designed to assess the overall nutritional status and nutrition related 
behaviour patterns of 8 to 12 year old school children in an urban area of Sri Lanka. Assessment of nutritional status showed a significant prevalence of overweight and obesity despite the high level of underweight, stunting and thinness and results were discussed in another paper ${ }^{1}$. This clearly shows that, as in many other Asian countries, Sri Lanka is in a nutritional transition but facing a double burden of over and under nutrition at this moment of time.

\section{Objective}

To provide information on nutritional status and dietary and physical activity patterns of 8-12 year old school children in an urban area of Sri Lanka.

\section{Subjects and methods}

Seven schools situated in Colombo were randomly selected. These schools showed a fair representation of children of all social levels. Students of years 4, 5, 6 and 7 were included. 50 students from each grade of each school were randomly selected and recruited into the study. The purpose of study was explained to the students and any withdrawals allowed.

Medical officers performed the anthropometric measurements. Height was measured using a stadiometer. Weight was measured using an electronic weighing scale (Secca ${ }^{\circledR}$, France) Medical assessment was done in all children who participated in study. To define obesity and overweight, sex and age specific body mass index (BMI) cutoffs recommended by International Obesity Task Force ${ }^{2}$ were used. Age and sex specific BMI 5th percentile from revised NCHS (2000) growth charts ${ }^{3}$ were used to define thinness. Information regarding physical activity and behaviour, feeding practices and socioeconomic factors were obtained using a pretested questionnaire filled by parent/guardian. Data was analyzed using Epi Info 2000 (CDC, USA) software.

\section{Results}

One thousand two hundred and sixty six children were recruited to the study. Data of 1224 subjects were used in the anthropometric analysis while 1102 data sets were used in analysis of dietary and physical activity, as the data of the remainder were not complete. Of the latter group $44 \%$ were boys.

Children belonged to 3 types of schools, private, public national and public non-national. 280 (25.4\%) were from private schools, 494 (44.8\%) from public national schools and $328(29.8 \%)$ from public nonnational schools.

Table 1 shows the characteristics of children that have been surveyed. First column shows data of the 1102 subjects used in analysis of dietary and physical activity while the second column shows data of the 1224 subjects used in the anthropometric analysis. 
Table 1

Characteristics of the population surveyed in this study

\begin{tabular}{|c|c|c|}
\hline 1 & 2 & \\
\hline \multicolumn{3}{|l|}{ Sex } \\
\hline Boys & $585(44 \%)$ & $588(48 \%)$ \\
\hline Girls & $617(56 \%)$ & $636(52 \%)$ \\
\hline \multicolumn{3}{|l|}{ Age } \\
\hline 8 & $141(12.8 \%)$ & $160(13.1 \%)$ \\
\hline 9 & $275(25.0 \%)$ & $305(25.0 \%)$ \\
\hline 10 & $240(21.8 \%)$ & $271(22.1 \%)$ \\
\hline 11 & $304(27.6 \%)$ & $317(25.9 \%)$ \\
\hline 12 & $142(12.8 \%)$ & $171(13.9 \%)$ \\
\hline \multicolumn{3}{|l|}{ Type of School } \\
\hline Public - National & $494(44.8 \%)$ & $543(44.3 \%)$ \\
\hline Public - Non national & $328(29.8 \%)$ & $332(27.2 \%)$ \\
\hline Private & $280(25.4 \%)$ & $349(28.5 \%)$ \\
\hline \multicolumn{3}{|l|}{ Number of children in the family } \\
\hline 1 & $167(15.1 \%)$ & \\
\hline 2 & $567(51.5 \%)$ & \\
\hline 3 & $284(25.8 \%)$ & \\
\hline 4 & $64(5.8 \%)$ & \\
\hline 5 & $20(1.8 \%)$ & \\
\hline \multicolumn{3}{|l|}{ Monthly family income in Rupees } \\
\hline$<5,000$ & $121(11.0 \%)$ & \\
\hline $5,000-10,000$ & $175(15.9 \%)$ & \\
\hline $10.000-15,000$ & $161(14.6 \%)$ & \\
\hline $15,000-20,000$ & $151(13.7 \%)$ & \\
\hline$>20,000$ & $418(37.9 \%)$ & \\
\hline Not answered & $76(6.9 \%)$ & \\
\hline \multicolumn{3}{|l|}{ Maternal education } \\
\hline Up to year 6 & $13(1.2 \%)$ & \\
\hline Year 6-9 & $49(4.4 \%)$ & \\
\hline GCE O/L & $312(28.3 \%)$ & \\
\hline GCE A/L & $474(43.0 \%)$ & \\
\hline Tertiary (Diploma or Degree) & $122(11.1 \%)$ & \\
\hline Not answered & $132(12.0 \%)$ & \\
\hline
\end{tabular}

1 
Table 2 shows the age and sex distribution of children with the mean height, weight and BMI for each category.

Table 2

Mean height, weight and BMI of school children according to age and sex (data of 1224 subjects)

\begin{tabular}{|c|c|c|c|c|}
\hline \multirow{2}{*}{ Age } & & Height & Weight & BMI \\
\cline { 2 - 4 } (years) & Number & Mean \pm SD & Mean \pm SD & Mean \pm SD \\
\hline Male & & & & \\
8 & & & $26.9 \pm 8.09$ & $15.7 \pm 3.92$ \\
9 & 135 & $129.7 \pm 6.72$ & $29.9 \pm 7.47$ & $16.5 \pm 3.01$ \\
10 & 140 & $133.8 \pm 6.58$ & $32.3 \pm 8.71$ & $16.7 \pm 3.20$ \\
11 & 142 & $138.2 \pm 7.64$ & $34.8 \pm 9.42$ & $17.1 \pm 3.53$ \\
12 & 82 & $147.1 \pm 8.80$ & $39.1 \pm 10.44$ & $17.6 \pm 3.43$ \\
& & & & \\
Female & & & & $15.3 \pm 2.15$ \\
8 & 77 & $127.9 \pm 6.13$ & $25.3 \pm 6.76$ & $15.8 \pm 2.86$ \\
9 & 170 & $133.2 \pm 6.57$ & $28.4 \pm 6.70$ & $16.5 \pm 3.19$ \\
10 & 131 & $138.4 \pm 8.66$ & $32.6 \pm 8.39$ & $17.8 \pm 3.86$ \\
11 & 175 & $145.0 \pm 8.20$ & $37.9 \pm 10.13$ & $18.3 \pm 3.67$ \\
12 & 83 & $150.8 \pm 7.83$ & $41.9 \pm 11.10$ & \\
\hline
\end{tabular}

Table 3 shows the time spent by children watching television each day, during weekdays as well as weekends. During weekdays majority spend less than 2 hours (82\%). During weekends children spend more time watching television each day. More than $48 \%$ spend more than 2 hours each day during the weekends. Table 3 also shows the time spent on outdoor physical activity during weekdays and weekends. Neither watching television nor outdoor physical activity showed a correlation to obesity and overweight.

Table 3.

Time spent each day on watching television and on physical activity (data of 1102 subjects)

\begin{tabular}{|c|c|c|c|c|}
\hline \multirow{2}{*}{$\begin{array}{c}\text { Time spent } \\
\text { (hours) }\end{array}$} & \multicolumn{2}{|c|}{ Watching Television } & \multicolumn{2}{c|}{$\begin{array}{c}\text { Physical activity } \\
\text { Outdoor) }\end{array}$} \\
& \multicolumn{2}{|c|}{} & \multicolumn{2}{c|}{ Week end (\%) } \\
\cline { 2 - 5 } & Week day (\%) & Week end (\%) & $168(15.2)$ & $218(19.8)$ \\
\hline None & $24(2.2)$ & $33(3.0)$ & $243(22.1)$ & $102(9.2)$ \\
$<1 \mathrm{hr}$ & $236(21.4)$ & $57(5.1)$ & $563(51.1)$ & $432(39.2)$ \\
$1-2 \mathrm{hrs}$ & $670(60.8)$ & $407(36.9)$ & $91(8.3)$ & $286(26.0)$ \\
$3-4 \mathrm{hrs}$ & $126(11.5)$ & $436(39.5)$ & $29(2.6)$ & $58(5.3)$ \\
$>5$ hrs & 0 & $92(8.3)$ & $8(0.7)$ & $6(0.5)$ \\
Don't know & $9(0.8)$ & $17(1.5)$ & 0 & 0 \\
Unanswered & $37(3.3)$ & $60(5.7)$ & & \\
& & & & \\
\hline
\end{tabular}


$80 \%$ of children attended tuition classes. Table 4 shows time spent by children of each category on tuition during weekdays and weekends. More than $50 \%$ of each category spent time on attending extra classes during weekdays as well as during weekends and it is almost equally distributed among all age groups. The type of school did not influence attending these extra classes (data not shown).

Table 4

Mean hours spent attending tuition classes per week during weekdays and weekends (data of 1102 subjects)

\begin{tabular}{|c|c|c|c|c|c|}
\hline \multirow[t]{2}{*}{ Age (yrs) } & \multirow[t]{2}{*}{ Total } & \multicolumn{2}{|c|}{ Tuition during week days } & \multicolumn{2}{|c|}{ Tuition during week ends } \\
\hline & & Number*(\%) & Mean \pm SD & Number*(\%) & Mean \pm SD \\
\hline 8 & 141 & $89(63.1)$ & $2.10 \pm 2.51$ & $77(54.6)$ & $1.46 \pm 1.66$ \\
\hline 9 & 275 & $165(65.7)$ & $2.42 \pm 2.75$ & $137(54.5)$ & $1.73 \pm 2.14$ \\
\hline 10 & 240 & $139(63.0)$ & $2.10 \pm 2.46$ & $130(58.8)$ & $2.10 \pm 2.54$ \\
\hline 11 & 304 & $186(68.4)$ & $2.30 \pm 2.53$ & $174(64.0)$ & $2.30 \pm 2.40$ \\
\hline 12 & 142 & $76(65.0)$ & $2.50 \pm 2.98$ & $69(59.0)$ & $1.90 \pm 2.17$ \\
\hline
\end{tabular}

* the total that attended tuition classes in each category

The 3 most favourite drinks were milk (32.6\%), fruit juices $(21.8 \%)$ and water $(9.6 \%)$. The 3 most popular food items were rice $(20.0 \%)$, chicken $(7.0 \%)$ and fruits $(6 \%)$. Table 5 gives the frequency of taking some selected food items. Eggs or fish were the commonest source of animal protein. The commonest meat product used was chicken and its consumption showed a clear relation to family income. Consumption of fruits was not very satisfactory. Majority consumed a fruit at a frequency of less than 3 times a week.

Table 5

Frequency of consumption of some selected food items (data of 1102 subjects)

\begin{tabular}{|c|c|c|c|c|c|}
\hline & $\begin{array}{c}6-7 \text { times/wk } \\
(\%)\end{array}$ & $\begin{array}{c}4-5 \text { times/wk } \\
(\%)\end{array}$ & $\begin{array}{c}1-3 \text { times /wk } \\
(\%)\end{array}$ & $\begin{array}{c}\text { Occasionally } 8 \\
(\%)\end{array}$ & $\begin{array}{c}\text { Does not take } \\
(\%)\end{array}$ \\
\hline Eggs & $32(2.9)$ & $178(16.1)$ & $656(59.5)$ & $193(17.5)$ & $43(4.0)$ \\
Fish & $217(19.7)$ & $298(27.0)$ & $459(41.6)$ & $70(6.3)$ & $58(5.4)$ \\
Chicken & $26(0.4)$ & $131(11.9)$ & $554(50.3)$ & $290(26.3)$ & $101(9.1)$ \\
Beef & $8(0.7)$ & $12(1.1)$ & $83(7.5)$ & $61(5.5)$ & $937(85.2)$ \\
Cheese & $19(1.7)$ & $86(7.8)$ & $315(28.6)$ & $492(44.6)$ & $190(17.3)$ \\
Pastries & $16(1.4)$ & $61(5.4)$ & $374(33.7)$ & $380(34.5)$ & $271(25.0)$ \\
Vegetables & $1102(100)$ & - & - & & $41(3.7)$ \\
Fruits & $430(39.0)$ & $308(28.0)$ & $264(24.0)$ & $59(5.3)$ & $91(8.3)$ \\
Chocolate & $65(5.9)$ & $128(11.6)$ & $383(34.7)$ & $435(39.5)$ & $11010.2)$ \\
Ice cream & $26(2.3)$ & $70(6.3)$ & $368(33.2)$ & $528(48.0)$ & $229(20.9)$ \\
Soft drinks & $71(6.4)$ & $107(9.7)$ & $299(27.1)$ & $396(35.9)$ & $588(53.4)$ \\
Pizza & 0 & $8(0.7)$ & $124(11.2)$ & $382(34.7)$ & \\
\hline
\end{tabular}

$\$$ frequency of once in 2 to 4 weeks 
Table 6 shows the correlation between nutritional status and family income. Prevalence of obesity and overweight increased with increase of family income whilst a high prevalence of thinness was seen among low-income groups.

Table 6

Nutritional status according to the family income(data of 1102 subjects)

\begin{tabular}{|l|c|c|c|c|}
\hline $\begin{array}{c}\text { Family income } \\
\text { Rupees per month }\end{array}$ & Number & $\begin{array}{c}\text { Obesity } \\
\mathbf{( \% )}\end{array}$ & $\begin{array}{c}\text { Overweight } \\
\mathbf{( \% )}\end{array}$ & $\begin{array}{c}\text { Thinness } \\
\mathbf{( \% )}\end{array}$ \\
\hline$<5,000121$ & $3(2.5)$ & $8(6.6)$ & $46(38.0)$ & \\
$5,000-10,000$ & 175 & 0 & $13(7.4)$ & $42(24.0)$ \\
$10,000-15,000$ & 161 & $4(2.5)$ & $15(9.3)$ & $48(29.8)$ \\
$15,000-20,000$ & 151 & $3(2.0)$ & $24(15.9)$ & $33(21.8)$ \\
$>20,000$ & 418 & $25(5.9)$ & $54(12.9)$ & $87(20.8)$ \\
Not declared & 76 & $3(3.9)$ & $10(13.1)$ & $12(15.8)$ \\
\hline
\end{tabular}

Medical inspection showed that dental caries was the commonest health problem. Highest prevalence was among children from public non-national schools $(48.7 \%)$, whilst public national and private schools had a prevalence of $10.5 \%$ and $11.8 \%$ respectively. Of the skin lesions commonest was scabies, and all cases were seen among children from public nonnational schools $(4.2 \%)$.

\section{Discussion}

Methods adopted in obtaining information regarding dietary and physical activity patterns of the children was based on the ability of parents/guardians on recalling the facts as well as judgment on the part of parents/guardians about the kind of food and type and duration of physical activity performed. Mainly observing the trends based on qualitative data rather than drawing conclusions based on quantitative data would minimize the biases arising from errors of judgment and recording. Although the problem of under nutrition is not controlled we are saddled with the problem of over nutrition too. The nutrition transition occurring in the region with the socioeconomic transformation has led to the double nutrition burden. With the increase of prevalence of overweight and obesity more related health problems such as diabetes mellitus, coronary heart disease and hypertension could be expected to be on the rise. Number of hours spent on watching television is not very high and it did not show any relation to obesity and overweight. Possible reason could be that our children do not have the habit of eating junk food while watching television. Amount of time spent on physical activity is quite satisfactory.

A very high number of school children had been attending tuition classes even at a very young age of 8 to 12 years. Specially spending time on weekdays to attend these has deprived them of valuable time, which could have been spent on other recreational activities.

Health status of children was fairly satisfactory except for prevalence of dental caries. Prevalence was high among low socio-economic groups. Children attending private and public national schools came from more or less equal socioeconomic groups and therefore most of the nutritional and behaviour indices were closely related whereas most children who attended public non-national schools were from low socio-economic classes and their health indices were mostly adversely affected.

Conclusion

The main factor that influenced the nutritional status and related behaviour was the socio-economic standard. Health programmes should be designed targetting these groups. 


\section{References}

1. Wickramasinghe $\mathrm{V}$ P, Lamabadusuriya $\mathrm{S} P$, Atapattu N, Sathyadas G, Kuruparananthan S, Karunarathne P, Nutritional status of children in an urban area of Sri Lanka. Ceylon Medical Journal 2004; 49(4): 114-8.

2. Cole T J, Bellizzi M C, Flegal K M, Dietz W H. Establishing a standard definition for child overweight and obesity worldwide: international survey. British Medical Journal 2000; 320:1-6.
3. CDC growth charts: United States; revised. Advance Data, U.S. Department of Health and Human Services, CDC,NCHS. 2000; 314:1-28. 
